\title{
Employee Empowerment in the Royal Commission at Yanbu
}

\author{
Abdulmonem Hamdan Alzalabani, David Mzembe \\ Yanbu Industrial College, Yanbu Industrial City, Saudi Arabia
}

\begin{abstract}
The purpose of this study is to find out if there are employee empowerment structures and programs in the Royal Commission at Yanbu; and if so whether they are operative. The research questions are: Is there an operative culture of employee empowerment? To what extent is formal power shared? To what extent is operational information shared? Are there any competency development programs in existence? Are employees supported in pursuance of organizational goals? Respondents were a sample of employees at the head office of the organization. The assessment strategy was a questionnaire of 36 items administered to $10 \%$ of employees ranging through all organizational levels. The questions aimed at obtaining evidence of existence of five components of employee empowerment, namely, a culture of employee empowerment, power and information sharing, employee competency development, and employee support. Under each component were a number of elements whose existence and activeness were directly tested by the questions. The responses to each item were rated in a 5-point Likert scale anchored at $1=$ strongly disagree and $5=$ strongly agree. Data was analyzed by presenting a table of frequencies of responses to each question testing the element(s). An element was considered highly operative if $80 \%$ or more of respondents chose the positive responses of agree or strongly agree; and the element was considered operative if between $60 \%$ and $79 \%$ of respondents chose the two options. If between $45 \%$ and $59 \%$ of the respondents chose the two options on the scale, the element was considered operative but deflated. If less than $45 \%$ of respondents chose the two options, the element was considered inactive or inoperative. The scores of all elements subscribing to an empowerment component were then averaged to find the score of the component. The findings showed that employee empowerment was an active phenomenon in the Royal Commission at Yanbu, albeit not so strong.
\end{abstract}

Keywords: assessment framework, employee empowerment, royal commission Yanbu directorate

\section{Literature Review}

Employee empowerment is difficult to positively define because it takes on different forms in different people and contexts (Zimmerman, 1990, p. 169). A dictionary definition of empowerment—“to give official authority to or delegate legal power to or to commission or authorize (Grove, 1971, p. 744) is similar to Gandz's view that empowerment means vesting decision-making or approval power in employees, where such

\footnotetext{
Abdulmonem Hamdan Alzalabani, Ph.D., Assistant Professor, Industrial Management Technology Department, Yanbu Industrial College.

David Mzembe, MBA, Lecturer, Industrial Management Technology Department, Yanbu Industrial College.

Correspondence concerning this article should be addressed to Abdulmonem Hamdan Alzalabani, Yanbu Industrial College, P.O. Box 30488, Yanbu Industrial City, Saudi Arabia. E-mail: alzalabani@yic.edu.sa.
} 
authority was a managerial prerogative (Gandz, 1990, p. 75). However, both definitions fail to encapsulate the entirety of the concept of employee empowerment as the term implies a great deal more than delegation. It is thus our view that a better understanding of employee empowerment can only be derived through exploring and analyzing the different forms it takes in different contexts.

Block (1987, p. 65) views empowerment from the point of view of the party being empowered. According to Block to feel empowered means to feel our survival is in our hands... we have an underlying purpose... we commit ourselves to achieving that purpose now. This definition corresponds with that of Caudron (1995, p. 28) who articulates employee empowerment as "when employees own their jobs, when they are able to measure and influence their individual success as well as the success of their departments and their companies". Implied in both definitions are a number of employee empowerment elements, including clarity of organizational purpose or goals, communication of employee performance through a fair performance evaluation and reward system, employee control or ownership of the job situation and employee commitment. Control and ownership of a job situation necessarily implies job enrichment and job satisfaction.

Bowen and Lawler (1992, p. 32) define empowerment as "sharing with front-line employees four organizational ingredients: information about the organizational performance... knowledge that enables employees to understand and contribute to organizational performance, rewards based on organizational performance, and power to make decisions that influence organizational direction and performance”. Bowen and Lawler (1995, p. 73) conclude that research suggests that empowerment exists when companies implement practices that distribute power, information, knowledge and rewards throughout the organization. It should be easy to note that in addition to delegation, Bowler and Lawler identify the same elements of employee empowerment as Caudron and Block above. However, the two authors go on to note that if any of the four elements is zero, nothing happens to redistribute that element, and empowerment will be zero (Bowen \& Lawler, 1995, p. 74).

The additive construct of Bowen and Lawler is also evident in Spreitzer's writing, who uses a combination of concepts to define empowerment. Spreitzer (1995) defines psychological empowerment as a motivational construct manifested in four cognitions: meaning, competence, self-determination and impact. One should be able to note the coincidence of the various definitions of employee empowerment around the stated elements. In Spritzer's definition meaning coincides with purpose or goals, competence coincides with control, self-determination coincides with autonomy or delegation of power and impact with feedback of performance. These four elements reflect an active rather than a passive orientation towards a work role; and they combine additively to create an overall construct of psychological empowerment. Spreitzer says lack of any single element will deflate the overall degree of felt empowerment. Note that while Bowen and Lawler say absence of one element will negate the distributive power of that element, Spreitzer maintains that absence of one element will rather deflate the overall degree of empowerment.

Some researchers provide definitions of empowerment that reflect their empirical observations or concepts that are precursors to empowerment. For example, Menon (1995) indicates, the empowered state as a cognitive state of perceived control, perceived competence and goal internalization. While Menon views empowerment as essentially a cognitive state, which means management can make employees perceive empowerment even in the absence of reality and still derive the benefits of employee empowerment, Conger and Kanungo (1998, p. 471) have assumed empowerment is an active process by which a leader or manager shares his or her power with subordinates. Power in this context is interpreted as actual possession of formal authority or control over 
organizational resources. This view of employee empowerment is so common that often employee participation is equated with empowerment. Moreover, the definition supposes that delegation of power over organizational resources is a way of providing resources and support to juniors.

Quinn and Spreitzer (1997, p. 38) indicate that empowerment in an organic sense is about understanding the needs of employees, modeling empowered behaviour, building teams, encouraging risk-taking, and trusting people to perform; while Thomas and Velthouse (1990) maintain that the word empowerment has become popular because it provides a label for a non-traditional paradigm of motivation. In this sense to empower means to motivate or energize.

Linda Hanold indicates that to be successful, each organization must create and define empowerment for itself. Empowerment must address the needs and culture of each unique entity (Hanold, 1997, p. 202). It is not surprising therefore that there are many definitions of employee empowerment. In the same spirit, we propose our own definition and model for understanding employee empowerment.

\section{Our Definition and Model}

Our definition of employee empowerment builds on a number of perspectives provided by various authors on the subject including those reviewed above. Employee empowerment is hereby defined as "A process by which a culture of empowerment is evolved, power and information is shared, employee competency is developed, and employee support is provided" (see Appendix A).

The above definition provides the basis of an employee empowerment model that has five interactive components, namely, empowerment culture (EC), power sharing (PS), information sharing (IS), employee competency development (CD), and employee support (ES). Under each component are a number of elements or factors with distributive or multiplicative properties.

The employee empowerment model that derives from the definition resembles a hut with a crown on the roof (see Appendix A). The crown or the apex of the "hut" represents the empowerment benefits as the ultimate goal of any empowerment effort or program. The roof represents the space in which the elements and components of empowerment interact and exchange their distributive, additive and multiplicative powers before releasing empowerment benefits to the organization. The third level of the hut (the walls) consists of the elements of employee empowerment grouped under their respective interactive components. The foundation of the hut is the environmental or cultural basis of empowerment; comprising pertinent organizational values and beliefs. The cultural environment feeds, and sets the tone for, all employee empowerment activities within the organization. The model, thus, maintains that effective employee empowerment should begin with evolution of an organizational culture that is conducive to, and supportive of, employee empowerment. Because organizational culture provides the environment within which empowerment activities take place, the model envisages that employee empowerment is not possible in the absence of conducive organizational values and beliefs. It is the underlying organizational cultural values and beliefs that inform and empower the elements that subscribe to the four empowerment components of power sharing, information sharing, competency development, and employee support.

It should be noted that components and elements of empowerment do not exist in watertight compartments, as they, in fact, are interactive. Components and elements have distributive, additive, and multiplicative properties when interacting with each other. In such a setting, an element of empowerment might as well be listed under more than one component. For example, providing access to organizational resources could be 
viewed as a way of sharing power as well as a way of providing support to employees. The model also supposes that the process of employee empowerment necessarily begins with addressing the elements before components are addressed. Should one element be absent or not addressed, the empowerment process loses the distributive power of the element, resulting in a deflationary effect on the component and the empowerment benefits as a whole.

\section{Empowerment Culture (EC): Values, Beliefs (and Assumptions)}

Edgar Schein defines organizational culture as a pattern of basic assumptions... that has worked well enough to be considered valid and, therefore, to be taught to new members as the correct way to perceive, think, and feel in relation to those problems (Schein, 1985, p. 9). These assumptions are a set of shared values and beliefs that are ingrained in the employees' mindset and subconsciously determine the way they behave, perceive and respond. Gandz (1990, p. 75) indicates that culture as "a set of shared values is needed and that beliefs about the way things should be done, the standards of behavior that are appropriate and the ethics of organizational actions do compel and propel behaviour”. Quinn and Spreitzer (1997, p. 40) also indicate that empowerment must be defined in terms of fundamental values, beliefs, and personal orientations.

Therefore, organizations that will have efficacious empowerment programs are those that have conducive values underpinning the empowerment efforts. Among these values are respect and appreciation for individual employees and the value they bring to the organization. Values alone do not make up an organization's culture, and respect for individuals is only one of the outward signs of an empowered culture. Organizational structure and reward systems are also basic assumptions that are part of the organization culture. Shein (1985, p. 244) supported this view by maintaining that culture affects most of the aspects of an organization-its strategy, its structure, its processes, its reward and control systems, and its daily routines. Other cultural values are belief in devolution of power, participation of employees in goal formulation and decision-making, and information sharing. Another basic assumption is whether individuals or groups (teams) should be rewarded for their efforts. Many organizations value individualism, but if teams are being promoted as a tool of empowerment and, on the other hand, individuals are being rewarded for the work of the team, then employees will unconsciously (or consciously) pick-up on the cultural norm and will be reluctant to dedicate themselves to the idea of team approach where their work may not be recognized and rewarded. Mallak and Kurstedt (1996) writes, "Managers who understand how empowerment integrates with organizational culture are motivated to lead employees... and help them internalize the values and traditions of empowerment (1985, p. 244)”.

\section{Power Sharing (PS)}

In an empowered organization the managers and supervisors take on different roles than they normally would in most organizations. One aspect of the role change is devolution of power and authority through the process of delegation down to lower levels of the organization and finally to empowered teams and individuals. Conger and Kanungo (1988) suggested that, like the concept of power, empowerment can be viewed in two ways. First, it can be viewed as a relational construct which implies the delegation of power. For instance Burke (1986) argued that to empower implies the granting of power and delegation of authority. Similarly, Sewell and Wilkinson (1992) suggested that for the use of the term empowerment of members to be meaningful, there must be a genuine shift in the locus of power away from management and to the shop floor.

Moreover, empowerment delegation implies a great deal more than delegation of authority to juniors, as it implies granting access to organizational resources necessary to pursue organizational goals. If employee 
empowerment is to be implemented successfully, controls over the resources must be removed and resources should be placed under the empowered employees' control. Resources include funding, materials, support staff, and expert advice on which the employee can draw (Ward, 1996, p. 22). Caudron (1995, p. 31) notes, once both employees and managers have received proper training, the next step is to give employees control of the resources needed to make improvements. Bowen and Lawler (1995) describe what happens if insufficient resources are provided. Relying on people to provide improvements without resources is called the human resources (HR) trap. The HR trap occurs when managers expect their front-line people to provide better and better service without simultaneously providing the necessary resources (Bowen \& Lawler, 1995, p. 82). Release of control to employees demonstrates management trust and confidence in their competence which is very empowering. Power sharing is also achieved through job enrichment. Job enrichment increases job depth, which refers to the ability and power an employee has to influence his or her work environment. It refers to the amount of discretion or decision opportunities an employee has in a job.

\section{Information Sharing (IS)}

Information is what organizational culture is made of and is the gatekeeper to power. People without information cannot act responsibly and if information shared is zero, nothing happens to redistribute empowerment; and empowerment will be zero (Bowen \& Lawler, 1995, p. 74). Communication and information are the lifeblood of empowerment (Ginnodo, 1997, p. 12). In the absence of information employees do not know the ramifications of their actions and therefore are not responsible. Caudron (1995, p. 28) in reporting about how to get the best from employees in Eastern European countries, he indicated that managers gave employees information about the business, invested in new skills training, set goals for employees and gave them ongoing feedback on how they were meeting those goals.

The importance of sharing information and effective communication about goals and plans, successes, and failures cannot be undervalued (Byham, 1997, p. 27). Randolph (1995, p. 22) shows research revealed that people who have information about current performance levels will set challenging goals—and when they achieve those goals they will reset the goals at a higher level. Spreitzer (1995) provides additional evidence of this value when she notes in her hypotheses that access to information about the mission of an organization, the performance of a work unit, and individual performance-based reward system are positively related to psychological empowerment. Spreitzer (1995, p. 1448) supports the hypothesis further by saying that information about mission is an important antecedent of empowerment because it helps to create a sense of meaning and purpose, and it enhances an individual's ability to make and influence decisions that are appropriately aligned with the organization's goals and mission.

An important element in information sharing is feedback about the employee's effectiveness. To make employee empowerment work, not only do we need to give them information about their own work, we must also give employees information about the business and let them know how their work fits in. Everyone wants to feel they are doing something of value. When you demonstrate the value that individuals bring to the business, people want to grow (Caudron, 1995, p. 29).

Effective information-sharing does not only imply effective organizational communication structures but also an effective management information system and information technology. It is imperative in a modern business environment to capture data and disseminate information for decision-making in a timely and empowering manner. 


\section{Competency Development (CD)}

In order to implement employee empowerment, the employees must be competent. Competency goes beyond developing job-task specific knowledge. Bowen and Lawler (1995, p. 80) cite the importance of training in which employees are familiarized with how their jobs fit into upstream and downstream activities. It does not make sense to empower employees to do things such as to make decisions or to approve or to initiate action if they are not properly trained (Gandz, 1990, p. 76). Caudron (1995, p. 32) indicates that once employees understand what needs to be done to improve the company they must have all the skills and resources necessary to be able to accomplish those improvements. Ginnodo (1997, p. 13) indicates that empowerment training is more than remedial; it prepares people for collaboration and higher level performance for the future. Ettorre (1997, p. 1) defines empowerment as employees having autonomous decision-making capabilities and acting as partners in the business, all with an eye to the bottom-line implications. Training does not come cheaply. Organizations seeking to empower employees through training should see to it that their training and development budgets are not underfunded.

\section{Employee Support (ES)}

Empowerment techniques and strategies that provide emotional support for subordinates and that create a supportive and trusting group atmosphere can be more effective in strengthening self-efficacy beliefs (Conger \& Kanungo, 1988). Support can also take the form of recognizing and rewarding improvement efforts and success (Ginnodo, 1997, p. 8). Reward and recognition systems... build pride and self-esteem (Byham, 1997, p. 27). Quinn and Spreitzer (1997, pp. 46-51) raise other aspects of support by noting that the fourth lever (of effecting empowering changes) is support and a sense of security. Every employee should have one or more sponsors who provide training, act as coach or mentor, and advocate with the compensation committee for the employee's pay increases. The sponsor tracks the employee's progress, providing help and encouragement... A sponsor is a friend and an associate. All the aspects of friendship are also present. Malone (1997) asserts that managers should act as coaches and help employees to solve problems in organization. Managers empower their subordinates by delegating responsibilities and assisting them when they have problems. This makes subordinates more satisfied with their managers in return they will perform to the manager's expectations. Employees need to be assisted in the process of empowerment. Managers frequently use coaching as one of the strategies in making empowerment successful in organization.

Employee empowerment significantly enhances job involvement, job satisfaction; career satisfaction and organizational commitment (Noorliza et al., 2006). Employee empowerment makes employees feel that they are valued in organizations and will create a high degree of job satisfaction and commitment. Employees are motivated by both intrinsic and extrinsic rewards.

\section{Benefits of Employee Empowerment}

Literature is abounding with evidence of employee empowerment benefits for organizations that implement it effectively. Kanter (1979, p. 73) indicates that organizational power can grow, in part, by being shared. By empowering others, a leader does not decrease his power; instead he may increase it. Kanter then uses the logic that the productive capacity of nations, like organizations, grows if the skill base is upgraded. Bowen and Lawler provide research evidence which shows that practices such as gain sharing, communication programs, work teams, job enrichment, skill-based pay, and so on has shown the results of these practices are consistent and positive. They go on to provide research evidence that empowerment may have a positive impact 
on a number of performance indicators. Respondents report that empowerment improves workers' satisfaction and quality of work life. Quality, service, and productivity are reportedly improved as a result of employee involvement efforts in about two-thirds of the companies. Approximately one-half of the companies also report that profitability and competitiveness have improved; this is supported by the finding of a relationship between empowerment and the firms' financial performance (Bowen \& Lawler, 1995, p. 75)

For those seeking softer evidence, Bowen and Lawler (1992) indicate empowered employees provide quicker on-line responses to customer needs during service delivery; quicker on-line responses to dissatisfied customers during service recovery; employees feel better about their jobs and themselves; employees will interact with customers with more warmth and enthusiasm. Randolph (1995, p. 22) indicates that a more subtle, yet very powerful benefit of employee empowerment was increased trust in the organization. People who have information about current performance levels will set challenging goals and when they achieve those goals they will reset the goals at a higher level (Randolph, 1995, p. 23). A number of authors also indicate that the increasing competitiveness of the global marketplace calls for better service and the benefit of drawing upon the entire pool of employees for creative ideas (Bowen \& Lawler, 1992; Gandz, 1990).

Empowering employees has shown to improve efficiency and reduce costs on the assembly line in a transmission plant (Suzik, 1998). Employee empowerment leads to job satisfaction, job involvement, loyalty, higher performance and faster service delivery to customers (Fulford \& Enz, 1995). Empowered employees make quick decisions and suggestions that improve quick service delivery in their sphere of operations and this saves a lot of money and time in organization (Sitterly, 1998). In addition, empowered employees provide exceptional customer service in several competitive markets and improve the profits of the organizations through repeated business (Bourke, 1998). Besides, employee empowerment promotes good relationship between the employee and the customers and the end result will be promoting good image of the organization in the environment (Potochny, 1998). Other benefits of employee empowerment in organization include reduced workload of the top management, improving training of employees and boost their morale. Employee empowerment fosters competitive climate and facilitates change in organization. In practice empowered employees have a high sense of self-efficiency, are given significant responsibility and authority over their jobs (Conger \& Kanungo, 1988; Ford \& Fottler; 1995; Quin \& Sprietzer, 1997).

\section{Case Study: Assessment of Employee Empowerment in the Royal Commission (RC)_-Yanbu Directorate}

\section{Assessment Framework}

Literature has many frameworks for assessing employee empowerment in organizations, including frameworks provided by Conger and Kanungo (1988, p. 474), Byham (1997, p. 25), Bowen and Lawler (1992, 1995). Our assessment method borrows from numerous frameworks. For example, from Quinn and Spreitzer (1997) we adopted the approach of establishing organizational characteristics that facilitate employee empowerment. From Randolph (1995), we adopted the approach of conducting a survey to determine if the empowering organizational characteristics or elements were present in an organization.

The strategy for assessing employee empowerment in the RC was a questionnaire of 36 items administered to $10 \%$ of employees ranging through all organizational levels during the month of September 2009. The responses from participants were allocated in a 5-point Likert scale of strongly agree, agree, not sure, disagree, and strongly disagree. The aim of the survey was to test the presence of employee empowerment in 
the Royal Commission and, thus, whether employee empowerment benefits accrued to the organization. Underpinning the questionnaire were the employee empowerment elements or characteristics sought to be established; grouped under specific empowerment components. The responses to the questions corresponding to each element indicated whether the characteristic or element was highly operative, operative, deflated, and inoperative in the organization. If an element was operative it was concluded the benefits of empowerment accrued to the organization on the basis that so far no research provides evidence that where empowerment was active there could be no empowerment benefits deriving. Rather the evidence is that where an element is absent, the empowerment process only loses that element's distributive power; which may in turn only deflate the overall empowerment.

An element was considered highly operative if $80 \%$ or more of respondents chose between the two options of agree or strongly agree in the Likert scale; and an element was considered operative if between $60 \%$ and $79 \%$ of respondents chose the two options. If between $45 \%$ and $59 \%$ of the respondents chose the two options in the scale, the element was considered operative but deflated. If less than $45 \%$ of respondents chose the two options, the element was considered inactive or inoperative.

After summing and averaging responses to questions relating to individual elements, data analysis resulted in conclusions on empowerment components tabulated in Table 1.

Table 1

Summary of Data Analysis Results and Conclusions (See Appendix B)

\begin{tabular}{lll}
\hline Component tested & $\begin{array}{l}\text { Mean \% age score ("agree” or } \\
\text { "strongly agree”) of elements }\end{array}$ & Comment \\
\hline Power sharing & 62 & Component is operative, but approaching deflation \\
Information sharing & 68.3 & Component is operative \\
Competency development & 62.8 & Component is operative \\
Employee support & 65.8 & Component is operative \\
Empowerment culture & 60.4 & Component is operative, but close to deflation point \\
\hline
\end{tabular}

At 68.3, information sharing seems the most operative element of employee empowerment in the RC; yet there is room for improvement on this component as well. Power sharing, competency development, and employee support are operative but necessarily low due to a weak culture of employee empowerment in the organization; which approaches deflation. Culture, as represented by organizational values, beliefs and assumptions forms the basis upon which all organizational processes are founded and sets the tone of all other activities. However, the overall employee empowerment efforts in the RC are at a level that guarantees some benefits to the organization. The extent to which empowerment benefits accrue cannot be determined. The data collection and analysis methods used are not capable of determining the extent. What is clear, though, is that the empowerment process is deflated and, therefore, empowerment benefits are not fully realized. For example the competency development component approaches a point of remarkable deflation because the element "training and development" under it was nearly inoperative and thus lost its distributive and multiplicative powers.

\section{Limitations}

The limitations of this research mainly relate to use Likert scales as data collection methods. Likert scales may be subject to distortion from several causes, including:

- Central tendency bias—-Respondents tending to avoid using extreme response categories; 
- Acquiescence bias-Respondents tending to agree with statements as presented;

- Social desirability bias-Respondents trying to portray themselves or their organization in a more favorable light.

Moreover, the data analyzed is cross sectional. It is envisaged more reliable positions would have been obtained had the data been collected over a period of time, since attitudes change with time.

\section{Conclusion}

Even though employee empowerment should mean different things to different people, it is clear numerous benefits would accrue to any organization and its employees by having the employees empowered in their work roles. The main strategies of employee empowerment recommended here are information and power sharing, development of employee competencies, support for employees in their work roles and workplace in general, and maintenance of a potent culture of employee empowerment.

This article should contribute to existing literature on employee empowerment and inspire human resource management academicians and practitioners to adopt the perspective shared by its authors in dealing with the question.

\section{References}

Block, P. (1987). The empowerment manager: Positive political skills at work. San Francisco: Jossey-Bass.

Bourke, J. F. (1998). Employee empowerment. Dallas Business Journal, 21(46).

Bowen, D. E., \& Lawler, E. E. (1992). Empowerment of service workers: What, why, how and when. Sloan Management Review, Spring, 31 .

Bowen, D. E., \& Lawler, E. E. (1995). Empowering service employees. Sloan Management Review, Summer, 73.

Burke, W. W. (1986). Leadership as empowering others. In S. Srivastva (Ed.), Executive power (p. 51), San Francisco, C.A.: Jossey-Bass.

Byham, W. C. (1997). Characteristics of an empowered organization. In Ginnodo, b. (Ed.) The power of Empowerment: What the Expert Say and 16 Actionable Case Studies. Arlington Heights, I.L.: Pride

Caudron, S. (1995). Create an empowering environment. Personnel Journal, 74(9), 28.

Conger, J. A., \& Kanungo, R. N. (1998). The empowerment process: Integration theory and practice. Academy of Management Review, 13(3), 471.

Ettorre, B. (1997, July). The empowerment gap: Hype vs. reality. HR Focus, 1.

Ford, R. C., \& Fottler, M. D. (1995). Empowerment: A matter of degree. Academy of Management Executvie, 9(3), 21.

Fulford, M. D., \& Enz, C. A. (1995). The impact of empowerment on service employees. Journal of Managerial Issues, 7(2), 161-175.

Gandz, J. (1990). The employee empowerment era. Business Quarterly, 55(2), 74.

Ginnodo, B. (Ed.). (1997). The power of empowerment: What the experts say and 16 actionable case studies. Arlington Heights, IL: pride.

Grove, P. B. (Ed.). (1971). Webster's third new international dictionary of the English Language Unabridged. Springfield, M.A.: G\&C Merriam.

Honold, L. (1997). A review of the literature on employee empowerment. Empowerment in Organizations, 5(4), 202.

Kanter, R. M. (1970). Power failure in management circuits. Harvard Business Review, 57(4), 65.

Mallak, L. A., \& Kursterdt, H. A. Jr. (1996). Understanding and using empowerment to change organizational culture. Industrial Management, 38(6), 8.

Malone, T. W. (1997). Is empowerment just a fad? Control, decision making and IT. Sloan Management Review, 23-35

Menon, S. T. (1995). Employee empowerment: Definition, measurement and construct validation (Unpublished doctoral dissertation, McGill University).

Potochny, D. K. (1998). Employee empowerment: Key to efficient customer service. Nation's Restaurant News, 32(32).

Quinn, R. E., \& Spreitzer, G. M. (1997). The road to empowerment: Seven questions a leader should consider. Organizational Dynamics, 26(2), 37. 
Randolph, W. A. (1995). Navigating the journey to empowerment. Organizational Dynamics, 23(4), 19.

Schein. E. H. (1985). Organizational culture and leadership. San Francisco: Jossey-Bass.

Sewell, G., \& Wilkinson, B. (1992). Empowerment or emasculation? Shopfloor surveillance in a total quality organization. In P.

Blyton, \& P. Turnbull (Eds.), Re-assessing human resource management. London: Sage.

Sitterly, C. (1998). Empowering others improves workplace quality. Business Press, 11(22).

Spreitzer, G. M. (1995). Psychological empowerment in the workplace: Dimensions, measurement, and validation. Academy of Management Journal, 38(5), 1442.

Suzik, H. A. (1998).Transmission plant is winner with empowerment. Quality, 37(4), 90-91.

Thomas, K. W., \& Velthouse, B. A. (1990). Cognitive elements of empowerment: An “interpretive” model of intrinsic task motivation. Academy of Management Review, 15(4), 666.

Zimmerman, M. A. (1990). Taking aim on empowerment research: On the distinction between individual and psychological conceptions. American Journal of Community Psychology, 18(1), 169.

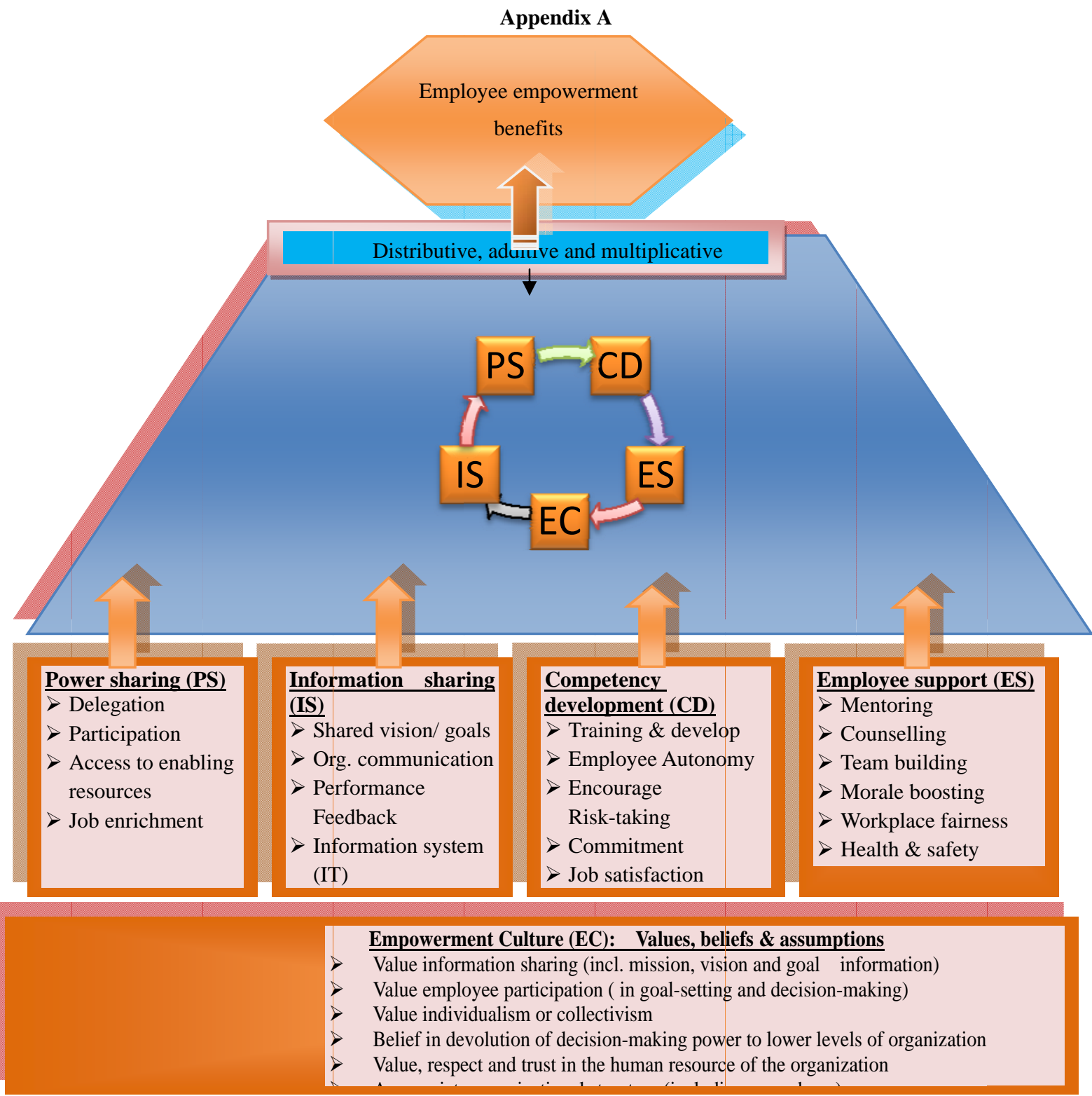

Figure A1. The employee empowerment model. 


\section{Appendix B}

Table B1

Employee Empowerment Elements Frequencies and Components Averages

\begin{tabular}{|c|c|c|c|}
\hline Element/Component tested & Corresponding question(s) & Average \% age score & Conclusion \\
\hline Power sharing & & 62 & Operative \\
\hline Delegation & $23 \& 26$ & 60.5 & Operative \\
\hline Participation & $24,25 \& 27$ & 57.3 & Deflated \\
\hline Access to enabling resources & 26 & 62.5 & Operative \\
\hline Job enrichment & $23 \& 32$ & 67.5 & Operative \\
\hline Information Sharing & & 68.3 & Operative \\
\hline Communication & $28,29 \& 30$ & 73.3 & Operative \\
\hline Shared vision/goals & $1,2,3, \& 5$ & 75.2 & Operative \\
\hline Feedback & $8 \& 27$ & 69.5 & Operative \\
\hline Information system & 4 & 55.1 & Deflated \\
\hline Competency development & & 62.8 & Deflated \\
\hline Training and development & $34 \& 35$ & 38.2 & Inoperative \\
\hline Autonomy & 32 & 76.3 & Operative \\
\hline Encourage risk-taking & $25,32, \& 34$ & 58.4 & Deflated \\
\hline Commitment & $5 \& 6$ & 63.1 & Operative \\
\hline Job satisfaction & $10 \& 36$ & 78.1 & Operative \\
\hline Employee support & & 65.8 & Operative \\
\hline Mentoring & $12 \& 18$ & 65.7 & Operative \\
\hline Counseling & $18 \& 33$ & 58.8 & Deflated \\
\hline Team building & $20,21,22, \& 23$ & 57.5 & Deflated \\
\hline Morale building & $8,10, \& 11$ & 73.4 & Deflated \\
\hline Fairness & $13 \& 14$ & 65.3 & Operative \\
\hline Health \& safety & $31 \& 33$ & 74.2 & Operative \\
\hline Empowerment culture & & 60.4 & Operative \\
\hline Value and trust workers & $17 \& 19$ & 73.1 & Operative \\
\hline Value information sharing & $28,29, \& 30$ & 73.4 & Operative \\
\hline Value employee participation & $24,25,26, \& 27$ & 58.5 & Deflated \\
\hline Belief in devolution of power & $23 \& 26$ & 60.6 & Operative \\
\hline Individualism and collectivism & 16 & 36.5 & Inoperative \\
\hline
\end{tabular}

